\title{
Lactoferrin-monophosphoryl lipid A complex enhances immunity of mice to Plesiomonas shigelloides CNCTC 138/92
}

\author{
Grzegorz Chodaczek ${ }^{1}$, Michal Zimecki ${ }^{1 \bowtie}$, Jolanta Lukasiewicz ${ }^{2}$ \\ and Czesław Lugowski ${ }^{2,3}$ \\ ${ }^{1}$ Department of Experimental Therapy, ${ }^{2}$ Department of Immunochemistry, Institute of Immunology \\ and Experimental Therapy, Polish Academy of Sciences, Wroctaw, Poland; ${ }^{3}$ Department of Cell Biology, \\ University of Opole, Poland
}

Received: 01 June, 2007; revised: 27 November, 2007; accepted: 30 November, 2007 available on-line: 30 January, 2008

\begin{abstract}
Our previous study showed the efficacy of lactoferrin-monophosphoryl lipid A isolated from Hafnia alvei LPS complex (LF-MPL H.a.) as an adjuvant in stimulation of humoral and cellular immune response in mice to conventional antigens and a lower pyrogenicity of the complex as compared with MPL ${ }^{\text {H.a. }}$ alone. In the present investigation we demonstrated that LF-MPL ${ }^{\text {H.a. }}$ complex enhanced the immunity of BALB/c mice immunized with Plesiomonas shigelloides CNCTC 138/92 bacterial vaccine, against $P$. shigelloides infection. The adjuvant effect was evidenced by a significant increase of the antigen-specific serum IgG, $\operatorname{IgG}_{2 a}$ and $\mathrm{IgG}_{1}$ and elevation of antigen-specific serum IgA concentrations. In addition, application of the adjuvant facilitated better clearance of the bacteria in spleens and livers of infected mice when compared with MPL ${ }^{\text {H.a. }}$ alone. These features of the new adjuvant may predispose it for vaccination protocols in humans.
\end{abstract}

Keywords: lactoferrin, monophosphoryl lipid A, adjuvant, Plesiomonas shigelloides

\section{INTRODUCTION}

Bacterial infections pose a serious threat despite the advances of modern medicine and pharmacology. Effective vaccinations, leading to long-term, specific immunity, may overcome that aggravating problem. Prophylactic immunizations require coadministrations of adjuvants, which substantially reduce the doses of the usually hazardous bacterial vaccines, providing at the same time adequate specific protection. Effective adjuvants are mostly of bacterial origin and their use is restricted to highly purified fractions of the bacterial cell wall (Gupta et al., 1993; Cox \& Coulter, 1997). Among that category of adjuvants, monophosphoryl lipid A (MPL) isolated from Salmonella minnesota R595, and related com- pounds, are most promising (Persing et al., 2002). In fact, MPL has been already accepted for use in humans (McCluskie \& Weeratna, 2001).

We recently described adjuvant property of lactoferrin (LF) in several models in mice (Zimecki \& Kruzel, 2000). LF is a multifunctional, milk-derived protein, exhibiting potent anti-inflammatory and anti-bacterial properties (reviewed in Legrand et al., 2005). The protein can bind to various cell types via different kinds of cell membrane receptors (reviewed in Suzuki et al., 2005). In addition, LF has an ability to bind lipopolysaccharide (LPS) and lipid A (Appelmelk et al., 1994), the phenomenon explaining, in part, its anti-inflammatory property (Legrand et al., 2005). In a very recent investigation we found that LF may also bind monophosphoryl lipid A isolated

\footnotetext{
${ }^{\square}$ Corresponding author: Michał Zimecki, Institute of Immunology and Experimental Therapy, Polish Academy of Sciences, Weigla 12, 53-114 Wrocław, Poland, e-mail: zimecki@iitd.pan.wroc.pl

Abbreviations: Ag, antigen; LF, lactoferrin; LPS, lipopolysaccharide; LF-MPL ${ }^{\text {H.a. }}$ complex of LF and MPL ${ }^{\text {H.a. }}$ MPL ${ }^{\text {H.a. }}$, monophosphoryl lipid A isolated from Hafnia alvei LPS; MALDI-TOF, matrix-assisted laser-desorption/ionization time-offlight; MPL, monophosphoryl lipid A; NMR, nuclear magnetic resonance; PBS, phosphate-buffered saline; RES, reticuloendothelial system; TT, tetanus toxoid.
} 
from Hafnia alvei PCM 1200 (MPL ${ }^{\text {H.a. }}$ ). The structure of $H$. alvei 1200 LPS was investigated by NMR spectroscopy, MALDI-TOF spectrometry, and chemical analysis. It was found that the structure of this lipid $\mathrm{A}$ is typical for enterobacteria and almost identical with that of Escherichia coli lipid A. The basic form of lipid A isolated from $\mathrm{H}$. alvei is identical to that of lipid A of Salmonella minnesota (Lukasiewicz \& Lugowski, unpublished). The LF-MPL ${ }^{\text {H.a. }}$ complex demonstrated potent adjuvant actions, surpassing those of LF or MPL ${ }^{\text {H.a. }}$ alone (Chodaczek et al., 2006). What was even more important, the LF-MPL ${ }^{\text {H.a. }}$ complex was less inflammatory in a foot pad edema test in mice (Chodaczek et al., 2006) and induced lower levels of tumor necrosis factor alpha in cell cultures than corresponding doses of MPL H.a. (unpublished).

The aim of this investigation was to evaluate the efficacy of the LF-MPL H.a. complex to enhance the immunity of $\mathrm{BALB} / \mathrm{c}$ mice against Gram-negative bacterial infection. Plesiomonas shigelloides infection in mice was used as a model since this Gram-negative enterobacterial rod is responsible for cases of waterand food-borne outbreaks of intestinal infections in human. It is one of the most frequent causes of travellers' diarrhoea in Japan and China (third position in rankings). Incidences of extra-intestinal infections, such as cellulitis, cholecystitis, peritonitis, proctitis, pyosalpinx, septic arthritis, endopthalmitis, meningitidis in neonates, bacteremia, sepsis, and septic shock have been noted for this bacterium. Sepsis and meningitides caused by $P$. shigelloides are associated with a serious course and high fatality rate (Stock, 2004). LPS as a constituent of its cell envelope is a main virulence factor of $P$. shigelloides.

Mice were immunized with neoglycoconjugate (nontoxic fragment of $P$. shigelloides LPS with tetanus toxoid) or a suspension of killed bacterial cells. The LPF-MPL ${ }^{\text {H.a. }}$ complex was used as an adjuvant. Specific antibody levels and ability of mice to eliminate bacteria from organs were determined after infection with $P$. shigelloides.

\section{MATERIALS AND METHODS}

Animals. BALB/c mice of both sexes, 8-12 weeks old, were used in the study. The mice were given standard pelleted food and filtered tap water ad libitum. Local, animal ethics committee approved the investigation.

Bacteria. Hafnia alvei PCM 1200 was obtained from the Polish Collection of Microorganisms (PCM), Institute of Immunology and Experimental Therapy (Wrocław, Poland). Plesiomonas shigelloides CNCTC (Czech National Collection of Type Culture) 138/92 (O68) were obtained from the collection of the $\mathrm{Na}$ tional Institute of Public Health (Prague, Czech Re- public). The bacteria were grown at $37^{\circ} \mathrm{C}$ on agar plates and harvested after $24 \mathrm{~h}$ by centrifugation and washed three times with saline. Dry mass of killed bacteria was obtained by treatment with $0.5 \%$ phenol solution followed by centrifuging in a CEPA flow laboratory centrifuge, washing with 31 of water and freeze-drying (Lukasiewicz et al., 2002).

Reagents. Low endotoxin bovine milk lactoferrin $(4.4 \mathrm{EU} / \mathrm{mg}$, $<25 \%$ iron saturated) was obtained from Morinaga Milk Industry Co. (Japan). MPL ${ }^{\text {H.a. }}$ from Hafnia alvei PCM1200 was isolated as described previously (Chodaczek et al., 2006). Lipopolysaccharides of $P$. shigelloides CNCTC 138/92 and $H$. alvei PCM 1200 were extracted from bacterial cells by the hot phenol/water method (Westphal \& Jann, 1965). A conjugate (PS138-TT) of polysaccharide (PS) isolated from P. shigelloides CNCTC 138/92 LPS with tetanus toxoid (TT) was prepared by the method of Jennings and Lugowski (Jennings \& Lugowski, 1981). The tetanus toxoid preparation was obtained from Biomed (Kraków, Poland).

Immunization of mice and administration of adjuvants. Mice were treated intraperitoneally (i.p.) with: $\mathrm{LF}(50 \mu \mathrm{g}), \mathrm{MPL}^{\text {H.a. }}(2.5 \mu \mathrm{g})$ or LF-MPL ${ }^{\text {H.a. }}$ $(50 / 2.5 \mu \mathrm{g})$ and immunized i.p. after $1 \mathrm{~h}$ with $0.2 \mathrm{ml}$ of a suspension of $P$. shigelloides cells $(0.5 \mu \mathrm{g} / \mathrm{ml} \mathrm{PBS})$. That was followed by a second and third immunization at weekly intervals. One week after the third immunization mice were bled for the determination of specific antibodies in serum.

In experiments with the PS138-TT conjugate mice were immunized subcutaneously with the antigen $(5 \mu \mathrm{g})$ admixed with analyzed adjuvants (LF $200 \mu \mathrm{g}$, MPL $^{\text {H.a. }} 25 \mu \mathrm{g}$, LF-MPL ${ }^{\text {H.a. }}$ 200/25 $\mu \mathrm{g}$ ). The procedure was repeated after three weeks and blood samples for antibody level measurements were collected after following three weeks.

Determination of $\mathrm{cfu}$ in organs. One week after the last dose of antigen, mice were given intravenously $1.5 \times 10^{8}$ bacteria and $24 \mathrm{~h}$ later spleens and livers were isolated. Appropriate dilutions of cell suspensions were applied onto agar plates and after an overnight incubation at $37^{\circ} \mathrm{C}$ colony-forming units (cfu) were counted. Experimental groups consisted of at least seven mice. The results were calculated as mean cfu numbers per mg of an organ \pm standard error $( \pm$ S.E.).

Determination of the levels of specific antibodies against $P$. shigelloides. Mice were bled under general anesthesia one week after the last immunization. Sera were isolated and kept frozen at $-20^{\circ} \mathrm{C}$ until determination of antibodies. Determination of immunoglobulin concentrations was performed according to a modified method described by (Lukasiewicz et al., 2003). Briefly, 96-well plates (Nunc) were coated using a $10 \mu \mathrm{g} / \mathrm{ml}$ solution of $P$. shigelloides LPS in $0.05 \mathrm{M}$ sodium carbonate/bicar- 
bonate buffer $(\mathrm{pH} 9.6)$ at room temperature for 2 $\mathrm{h}$ and further $16 \mathrm{~h}$ at $4^{\circ} \mathrm{C}$. The plates were washed three times with $50 \mathrm{mM}$ Tris buffer containing 150 $\mathrm{mM} \mathrm{NaCl}, \mathrm{pH} 7.5$ (TBS) and blocked with $2 \%$ casein (BDH Biochemical) in TBS at room temp. for $2 \mathrm{~h}$. Next, the plates were washed once and the wells were filled with sera diluted in TBS containing $0.2 \%$ casein. Following $2 \mathrm{~h}$ of incubation and three washes, horseradish peroxidase-conjugated antibodies specific for mouse IgG (Fc-specific) (Sigma), $\operatorname{IgG}_{2 a^{\prime}} \operatorname{IgG}_{1}$ or IgA (Santa Cruz Biotechnology) were added and incubated for next $2 \mathrm{~h}$. Color was developed with o-phenylenediamine (Sigma) in 0.1 $\mathrm{M}$ citrate buffer ( $\mathrm{pH}$ 5.0) containing $0.01 \% \mathrm{H}_{2} \mathrm{O}_{2}$. Absorbance was measured at $490 \mathrm{~nm}$ and reference wavelength of $550 \mathrm{~nm}$ using a colorimetric reader (Dynatech 5000). Results are presented as mean absorbance values from seven mice per group.

Statistics. Experimental groups consisted of at least seven mice and the experiments were repeated twice. The results were analyzed using STATISTICA 6.1. software. The Levene's test was used to determine the homogeneity of variance between groups. When the variance was homogeneous, analysis of variance (ANOVA) was applied, followed by post hoc comparisons with the Tukey's test to estimate the significance of the difference between groups. Nonparametric data were evaluated by the KruskalWallis analysis of variance on ranks. Significance was determined at $P \leq 0.05$.

\section{RESULTS}

Effects of the LF-MPL ${ }^{\text {H.a. }}$ complex on the generation of specific antibodies to $P$. shigelloides

Preliminary experiments (not shown) established a suboptimal dose of antigen $(0.1 \mu \mathrm{g} /$ mouse of a suspension of killed P. shigelloides CNCTC 138 bacterial cells). Mice were immunized with the antigen and treated with the adjuvants as described above. The results showed that application of the adjuvants elevated the serum content of antigenspecific $\operatorname{IgG}$ and $\operatorname{IgG}_{2 a}$ (Figs. 1 and 2). Although LF alone tended to decrease the antibody concentration, when complexed with MPL ${ }^{\text {H.a. }}$ it elevated the antibody concentration by over two-fold as compared with the group of mice immunized with the antigen only. The only statistically significant increase of the antibody level was found in the group of mice treated with the complex versus the respective control (no adjuvant). Both MPL ${ }^{\text {H.a. }}$ and the complex also elevated the content of $\mathrm{IgG}_{1}$ (Fig. 3) and IgA (Fig. 4) antibodies. These effects were, however, not statistically significant in the case of

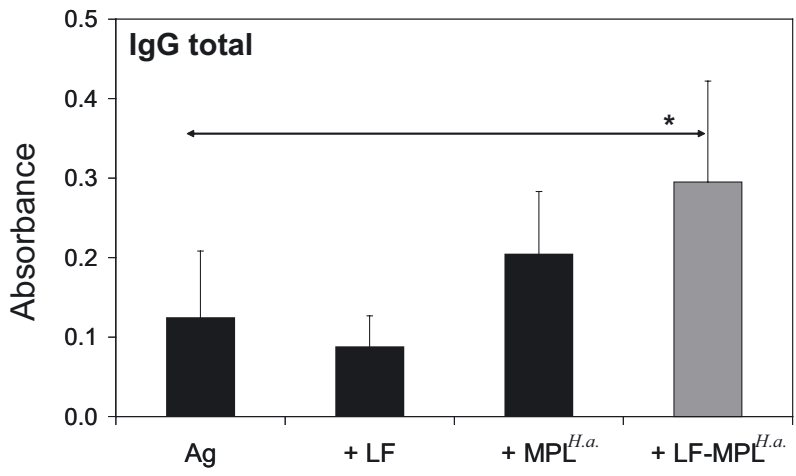

Figure 1. Effects of adjuvants on serum levels of specific IgG antibodies against Plesiomonas shigelloides.

Mice were immunized as described in Materials and Methods with suspension of killed P. shigelloides (Ag 0.1 $\mu \mathrm{g}$ ) following administration of PBS or adjuvants (LF 50 $\mu \mathrm{g}$, MPL H.a. $2.5 \mu \mathrm{g}$ or LF-MPL ${ }^{\text {H.a. }} 50 / 2.5 \mu \mathrm{g}$ ). The results are shown as mean absorbance values from seven mice per group $\left(40 \times\right.$ dilution of serum). ${ }^{*} P<0.05$.

IgA despite a quite marked (two-fold) increase of the antibody levels.

\section{Effects of the LF-MPL ${ }^{\text {H.a. }}$ complex on the clearance} of $P$. shigelloides from the organs of infected mice

Mice were immunized with a bacterial vaccine containing adjuvants as described in the Materials and Methods. One week after the last immunization the mice were injected with $4 \times 10^{8}$ of bacteria and the cfu numbers were determined in spleens and livers. All immunized mice killed the bacteria much more efficiently than naïve mice $(30-40 \times$ reduction in cfu numbers). The destruction of bacteria underwent differently in the spleens (Fig. 5) than in the livers (Fig. 6), where the process of bacteria elimination was overall much more effective. In both organs the cfu numbers attained the lowest values in mice treated with LF-MPL ${ }^{\text {H.a. }}$. In spleens, statisti-

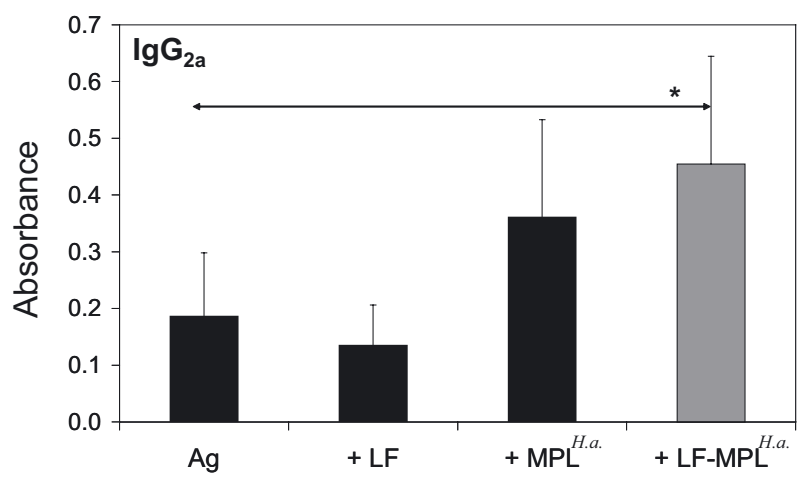

Figure 2. Effects of adjuvants on serum levels of specific IgG $_{2 \mathrm{a}}$ antibodies against Plesiomonas shigelloides.

The procedure as in Fig. $1 .{ }^{*} P<0.05$. 


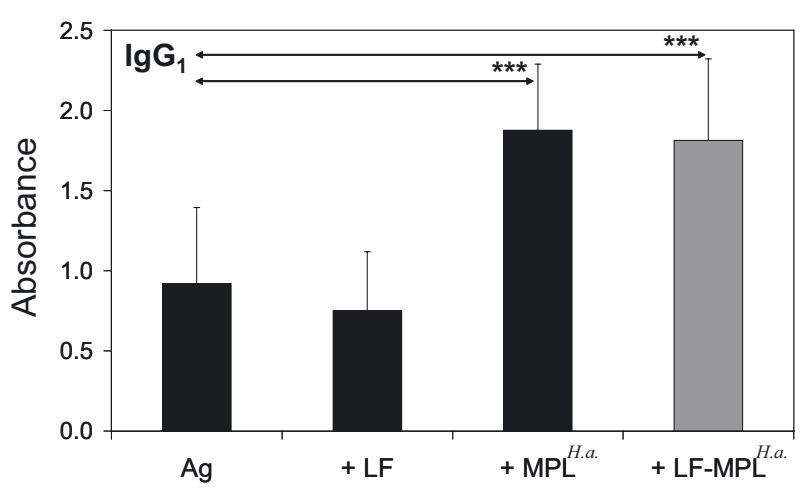

Figure 3. Effects of adjuvants on serum levels of specific $\mathrm{IgG}_{1}$ antibodies against Plesiomonas shigelloides.

The procedure as in Fig. 1. ${ }^{* *} P<0.001$.

cally significant differences were found for comparisons with the naïve mice group: $\mathrm{MPL}^{\text {H.a. }}(P<0.05)$ and LF-MPL H.a. $(P<0.001)$. In the livers, statistically significant clearance of bacteria was registered only for the LF-MPL ${ }^{\text {H.a. }}$ group: LF-MPL ${ }^{\text {H.a. }}$ /naïve mice $(P<0.05)$ and LF-MPL ${ }^{\text {H.a. }} / \mathrm{Ag}(P<0.05)$.

\section{DISCUSSION}

In this investigation we confirmed and extended to new experimental models our recent findings that the LF-MPL ${ }^{\text {H.a. }}$ complex is a potent adjuvant in generation of both cellular and humoral immune response in mice. The immunostimulatory effect of the LF-MPL ${ }^{\text {H.a. }}$ complex exceeded that of MPL ${ }^{\text {H.a. }}$ alone; on the other hand, an equivalent dose of LF as in the complex did not enhance the specific immunoglobulin production. That phenomenon is in accord with our previous data showing that LF tended rather to stimulate cellular responses (OVA, ovalbumin; BCG) and our unpublished data indicating that it may also diminish antibody production to ovalbumin. On the other hand, LF was able to up-regulate

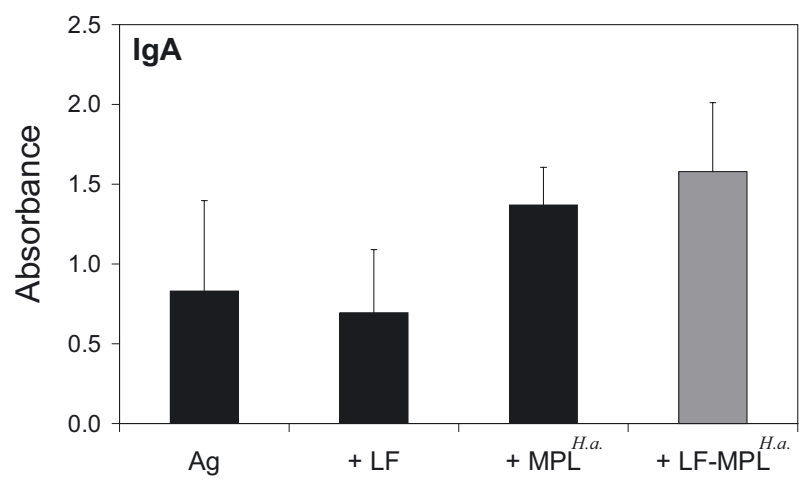

Figure 4. Effects of adjuvants on serum levels of specific IgA antibodies against Plesiomonas shigelloides. The procedure as in Fig. 1.

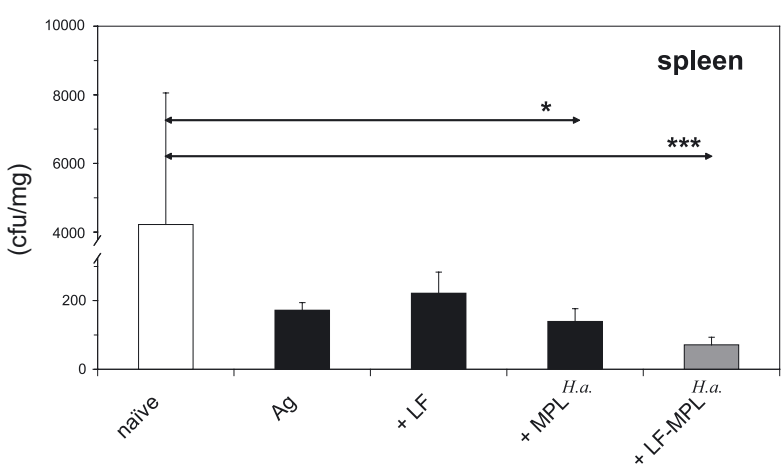

Figure 5. Effects of adjuvants on clearance of Plesiomonas shigelloides in spleens of immunized mice $24 \mathrm{~h}$ following infection.

The results are presented as mean cfu numbers per mg of spleen \pm S.E. ${ }^{* *} P<0.001 ;{ }^{*} P<0.05$.

the humoral immune response to suboptimal doses of sheep red blood cells (Zimecki \& Kruzel, 2000) and to increase, upon oral administration, both local and systemic antibody response (Debbabi et al., 1998). In addition, LF inhibited the activity of Th1 but not Th2 antigen-specific T-cell lines (Zimecki et al., 1996). Application of LF in the complex revealed a dual nature of this protein regarding a preferential support of a given type of the immune response. In this report we showed that combination of the two adjuvants (LF and MPL ${ }^{\text {H.a. }}$ ) led to an enhancement of both types of the immune response. That was in accord with our previous findings (Chodaczek et al., 2006) revealing stimulation of both the humoral immune response to sheep erythrocytes and the cellular immune response (delayed type hypersensitivity) to ovalbumin. The complex increased production of $I G_{2 a}$ antibodies, characteristic for IFN $\gamma$-mediated cellular response, and also $\operatorname{IgG}_{1}$ antibodies, predominant in the humoral immune response (Stevens et

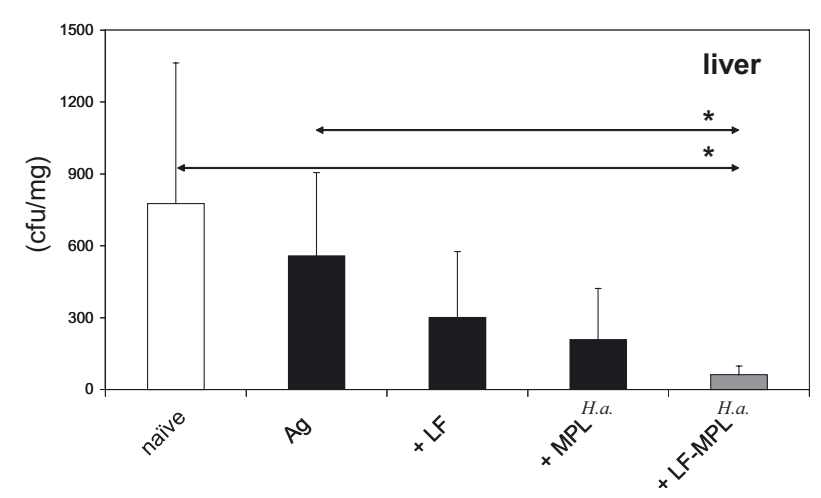

Figure 6. Effects of adjuvants on clearance of Plesiomonas shigelloides in livers of immunized mice $24 \mathrm{~h}$ following infection.

The results are presented as mean cfu numbers per mg of liver \pm S.E. ${ }^{*} P<0.05$. 
al., 1988). Nevertheless, both the total IgG and IgA antibody contents were higher upon application of the complex as compared to MPL ${ }^{\text {H.a. }}$ alone. The stimulation of OVA-specific antibodies of the $\mathrm{IgG}_{2 \mathrm{a}}$ and $\mathrm{IgG}_{1}$ subclasses by the complex was also reported in our previous study (Chodaczek et al., 2006). Thus, the LF-MPL ${ }^{\text {H.a. }}$ complex appears to be universal in augmenting both types of immune response.

Adjuvant (the LF-MPL ${ }^{\text {H.a. }}$ complex) did not elevate antibody production to $P$. shigelloides (not shown) when purified O-specific polysaccharide isolated from P. shigelloides CNCTC 138/92 LPS was used in complex with tetanus toxoid (PS138-TT). The simplest explanation of that phenomenon is that tetanus toxoid, as a protein carrier, generates optimal stimulation of the immune response for PS138 which cannot be further enhanced by other adjuvants. That, of course, indicates limitations for use of the LF-MPL H.a. adjuvant in such cases.

Apart of the stimulation of specific antibody levels, the LF-MPL ${ }^{H . a}$ complex enhanced the ability of infected mice to eliminate bacteria from organs belonging to the reticulo-endothelial system (RES). The adjuvant effect of the complex was better pronounced in the liver, probably because most of the bacterial killing takes place as a consequence of cooperation between neutrophils nad Kuppfer cells (Gregory et al., 2002). Opsonization of bacteria by specific antibodies could facilitate that process. Interestingly, LF alone has also been shown effective in increasing clearance of bacteria in organs of infected mice (Zagulski et al., 1989). It is possible that the LF constituent of the complex could contribute to that process by increasing the killing of bacteria by RES cells (Zagulski et al., 1989) and by recruitment of neutrophils (Zimecki et al., 2004). We also found (not shown) that intraperitoneal administration of the complex $(2 / 0.1 \mathrm{mg})$ elevated very significantly (from 16.8 to $34.4 \%$ ) the percentage of circulating blood neutrophils and neutrophil precursors (from $0.2 \%$ to $5.4 \%) 24 \mathrm{~h}$ post injection, substantially enlarging the pool of major phagocytes. It seems, therefore, that the application of the complex in the immunization protocol may stimulate both the specific and innate immune response.

As previously proposed (Chodaczek et al., 2006), the efficacy of the LF-MPL ${ }^{H \cdot a}$ complex could result from concomitant triggering of antigen-presenting cells by different kinds of cellular receptors. MPL typically interacts with cells via TLR (Tolllike receptors) (Martin et al., 2003), and bovine LF through receptors with affinity for mannose (Zimecki et al., 2002). Interaction of LF with cells via other types of receptors (Suzuki et al., 2005) is also possible. In addition, induction of cytokines by LF, such as TNF- $\alpha$, IL-12 and IL-15, relevant in the initiation of the immune response may also be of importance (Actor et al., 2002).

An obvious beneficial feature of the LF-MPL ${ }^{H . a}$ adjuvant is its low pyrogenicity, i.e. lower induction of pro-inflammatory cytokines in cell cultures (not shown) as compared to equivalent doses of MPL ${ }^{H}$. a. Subcutaneous injection of the complex in mice resulted also in a smaller inflammatory reaction when compared with a corresponding dose of MPL ${ }^{\text {H.a. }}$ (not shown). This is a desired property of newly designed adjuvants, and together with the superiority of the LF-MPL ${ }^{\text {H.a. }}$ complex over MPL ${ }^{\text {H.a. }}$ in augmenting specific immune response, makes it attractive for further research.

\section{Acknowledgements}

Part of this study concerning structural analysis of Hafnia alvei lipid A and monophosphoryl lipid A was supported by grant N401 084 32/1944 from the Ministry of Sciences and Higher Education.

\section{REFERENCES}

Actor JK, Hwang SA, Olsen M, Zimecki M, Hunter RL Jr, Kruzel ML (2002) Lactoferrin immunomodulation of DTH response in mice. Int Immunopharmacol 2: 475486.

Appelmelk BJ, An YQ, Geerts M, Thijs BG, de Boer HA, MacLaren DM et al. (1994) Lactoferrin is a lipid Abinding protein. Infect Immun 62: 2628-2632.

Chodaczek G, Zimecki M, Lukasiewicz J, Lugowski C (2006) A complex of lactoferrin with monophosphoryl lipid $\mathrm{A}$ is an efficient adjuvant of the humoral and cellular immune response in mice. Med Microbiol Immunol (Berl). 195: 207-216

Cox JC, Coulter AR (1997) Adjuvants - a classification and review of their modes of action. Vaccine 15: 248-256.

Debbabi H, Dubarry M, Rautureau M, Tome D (1998) Bovine lactoferrin induces both mucosal and systemic immune response in mice. J Dairy Res 65: 283-293.

Gregory SH, Wing EJ (2002) Neutrophil-Kupffer cell interaction: a critical component of host defenses to systemic bacterial infections. J Leukoc Biol 72: 239-248.

Gupta RK, Relyveld EH, Lindblad EB, Bizzini B, BenEfraim S, Gupta CK (1993) Adjuvants - a balance between toxicity and adjuvanticity. Vaccine 11: 293-306.

Jennings HJ, Lugowski C (1981) Immunochemistry of groups $\mathrm{A}, \mathrm{B}$, and $\mathrm{C}$ meningococcal polysaccharide-tetanus toxoid conjugates. J Immunol 127: 1011-1018.

Legrand D, Elass E, Carpentier M, Mazurier J (2005) Lactoferrin: a modulator of immune and inflammatory responses. Cell Mol Life Sci 62: 2549-2559.

Lukasiewicz J, Jachymek W, Niedziela T, Malik-Gebicka M, Dzieciatkowska M, Lugowski C (2002) Comparison of serological specificity of anti-endotoxin sera directed against whole bacterial cells and core oligosaccharide of Escherichia coli J5-tetanus toxoid conjugate. Acta Biochim Polon 49: 721-734.

Lukasiewicz J, Jachymek W, Niedziela T, Dzieciatkowska M, Lakomska J, Miedzybrodzki R et al. (2003) Serological characterization of anti-endotoxin serum directed 
against the conjugate of oligosaccharide core of Escherichia coli type R4 with tetanus toxoid. FEMS Immunol Med Microbiol 37: 59-67.

Martin M, Michalek SM, Katz J (2003) Role of innate immune factors in the adjuvant activity of monophosphoryl lipid A. Infect Immun 71: 2498-2507.

McCluskie MJ, Weeratna RD (2001) Novel adjuvant systems. Curr Drug Targets Infect Disord 1: 263-271.

Persing DH, Coler RN, Lacy MJ, Johnson DA, Baldridge JR, Hershberg RM et al. (2002) Taking Toll : lipid A mimetics as adjuvants and immunomodulators. Trends Microbiol 10: S32-37.

Stevens TL, Bossie A, Sanders VM, Fernandez-Botran R, Coffman RL, Mosmann TR et al. (1988) Regulation of antibody isotype secretion by subsets of antigen-specific helper T cells. Nature 334: 255-258.

Stock, I. (2004) Plesiomonas shigelloides: an emerging pathogen with unusual properties. Rev Med Microbiol 15: 129-139.

Suzuki YA, Lopez V, Lonnerdal B (2005) Mammalian lactoferrin receptors: structure and function. Cell Mol Life Sci 62: 2560-2575.

Westphal O, Jann K (1965) Bacterial lipopolysaccharides: extraction with phenol-water and further applications of the procedure. Methods Carbohydr Chem 5: 83-89.
Zagulski T, Lipinski P, Zagulska A, Broniek S, Jarzabek Z (1989) Lactoferrin can protect mice against a lethal dose of Escherichia coli in experimental infection in vivo. Br J Exp Pathol 70: 697-704.

Zimecki M, Kruzel ML (2000) Systemic or local co-administration of lactoferrin with sensitizing dose of antigen enhances delayed type hypersensitivity in mice. Immunol Lett 74: 183-188.

Zimecki M, Mazurier J, Spik G, Kapp JA (1996) Lactoferrin inhibits proliferative response and cytokine production of TH1 but not TH2 cell lines. Arch Immunol Ther Exp (Warsz) 44: 51-56.

Zimecki M, Kocieba M, Kruzel M (2002) Immunoregulatory activities of lactoferrin in the delayed type hypersensitivity in mice are mediated by a receptor with affinity to mannose. Immunobiology 205: 120-131.

Zimecki M, Artym J, Chodaczek G, Kocieba M, Kruzel ML (2004) Protective effects of lactoferrin in Escherichia coliinduced bacteremia in mice: relationship to reduced serum TNF alpha level and increased turnover of neutrophils. Inflamm Res 53: 292-296. 